\title{
Determination, through Derivatization and GC-MS Analysis, of Omega-3 and Omega-6 Fatty Acids in Fish Oil Capsules Sold in Salvador, Bahia
}

\author{
Milena S. C. Brotas, ${ }^{a}$ Graziele A. Carvalho ${ }^{a}$ and Pedro A. P. Pereira ${ }^{(*, a, b, c}$ \\ ${ }^{a}$ Instituto de Química, Universidade Federal da Bahia, 40170-115 Salvador-BA, Brazil \\ ${ }^{b}$ Centro Interdisciplinar de Energia e Ambiente (CIEnAm), Universidade Federal da Bahia, \\ 40170-290 Salvador-BA, Brazil
}

'INCT E\&A, Universidade Federal da Bahia, 40170-115 Salvador-BA, Brazil

\begin{abstract}
The essential $\omega-3$ and $\omega-6$ fatty acids have important physiological functions, such as prevention of cardiovascular diseases and atherosclerosis, and are commercially sold as fish oil capsules. In the present work, a method previously described in the literature, based on the derivatization of polyunsaturated fatty acids and their gas chromatography-mass spectrometry (GC-MS) analysis in the form of methyl esters, was partially modified and optimized for determination of $\omega-3$ and $\omega-6$ fatty acids in fish oil capsules. In addition, the $\omega-9$ fatty acid oleic acid was also determined with the optimized method, despite the lack of information about its quantities in the acquired products. The method exhibited good linearity and precision, limits of detection and quantification in the ranges from 0.16 to $0.18 \mathrm{mg} \mathrm{g}^{-1}$ and 0.46 to $0.63 \mathrm{mg} \mathrm{g}^{-1}$, respectively, and recoveries above $76 \%$. The method was applied to analyze ten brands of encapsulated fish oil marketed in Salvador, BA, Brazil. Amongst the results, it was shown that one brand had significantly high amounts of linoleic acid, which indicates a probable adulteration of the product.
\end{abstract}

Keywords: fish oil, $\omega-3$ and $\omega-6$ supplements, commercial brands, fatty acids content, GC-MS analysis

\section{Introduction}

The benefits of polyunsaturated fatty acids (PUFAs) intake are directly related to prevention and treatment of cardiovascular diseases, ${ }^{1}$ reduction of atherosclerosis, improvement of endothelial function, reduction of blood pressure, prevention of the gastrointestinal tract diseases and infections, and inhibition of lesions and immunological changes in athletes, ${ }^{2}$ as well as to exhibit anti-inflammatory properties. $^{3-6}$

Polyunsaturated fatty acids include the families of $\omega-9, \omega-6$, and $\omega-3$ fatty acids, represented by oleic acid (C18:1, $\omega-9)$, linoleic acid (C18:2, $\omega-6)$, linolenic acid (C18:3, $\omega-3)$, eicosapentaenoic acid (EPA, C20:5, $\omega-3$ ) and docosahexaenoic acid (DHA, C22:6, $\omega-3$ ), respectively. ${ }^{7,8}$

The fatty acids $\omega-3$ and $\omega-6$ are essential fatty acids, since they cannot be synthesized by the human organism. ${ }^{9,10}$ Thus, they must be included in an individual's diet and can be obtained through the food intake, especially fish and seafood. On the other hand, $\omega-9$ fatty acids are conditionally

*e-mail: pedroapp@ufba.br essential, since they can be produced by the body from other fatty acids. ${ }^{11,12}$ Oleic acid, which represents the $\omega-9$ family, is present in the triacylglycerols of several edible oils, such as rapeseed, soybean, palm, cotton seed, peanut and sunflower oils, which account together for more than $80 \%$ of the world's vegetable oil production. ${ }^{13}$

Several health organizations recommend persons to intake polyunsaturated fats, especially $\omega$ - 3 long-chain polyunsaturated fatty acids, such as EPA and DHA, to help reduce the risk of chronic diseases, such as cardiovascular diseases. ${ }^{14,15}$ Due to this, the demand has increased for foods which are rich in these acids, as well as for dietary supplements rich in PUFAs, particularly with regard to EPA and DHA. ${ }^{16}$

Fish oil supplements are produced mainly from sole and salmon type fish, but also from cod liver oil and whale oil, since they contain large amounts of PUFAs, especially EPA and DHA. ${ }^{17}$ These supplements are usually found as concentrated capsules in the form of triacylglycerol esters.

Dietary supplementation using fish oil nutritional capsules is a viable alternative for PUFAs intake. Although consumption of PUFAs has associated health benefits, 
according to the Brazilian Association of Cardiology, ${ }^{18}$ the optimal effects for these supplements are directly related to their dosage. Therefore, fatty acids should be consumed in an adequate proportion.

There are different techniques which can be applied in the analysis of fatty acids in oils and fats, such as, for example, nuclear magnetic resonance, ${ }^{19}$ infrared spectroscopy ${ }^{17}$ and chromatography. Chromatographic methods are widely used in the determination of saturated, mono and polyunsaturated fatty acids, in foods and biological samples. ${ }^{20-23}$ The main advantages presented by them are the fast separation of mixtures containing different types of acids, together with the high sensitivity provided by different types of detectors, such as mass spectrometers.

In this way, studies for determining the polyunsaturated fatty acids in fish oil capsules have been reported, mainly using high performance liquid chromatography (HPLC), ${ }^{24}$ liquid chromatography coupled to mass spectrometry (LC-MS), ${ }^{25}$ and gas chromatography coupled to mass spectrometry (GC-MS). ${ }^{6,14,20}$

GC-MS has advantages, such as combining a relatively low cost together with high sensitivities, when compared to the other described techniques, ${ }^{26}$ thus making it widely used in the analysis of foods, especially in the determination of volatile organic compounds and qualitative and quantitative determinations of fatty acids, steroids, alcohols, oils and low molecular weight carbohydrates. ${ }^{27}$ It is worth mentioning, however, that in order to perform the analysis of fatty acids, it becomes necessary to carry out derivatization procedures, in order to transform them into their respective volatile fatty acid methyl esters (FAMEs).
This work aimed to apply a method, previously described in the literature, ${ }^{26}$ which was partially modified and optimized, based on the derivatization of polyunsaturated fatty acids and their GC-MS analysis in the form of methyl esters, in the determination of $\omega-3$ and $\omega-6$ essential fatty acids, with emphasis on EPA and DHA, in fish oil capsules of different brands available on the market in Salvador, Bahia State, Brazil. A comparison was then done between brands, as well as between the values reported by the manufacturers and those found in this work.

The relevance of the theme is justified by the wide variety of brands available on the market, the possible variability of composition between different brands and between batches of a same brand, as well as the possibility of product adulteration by unscrupulous manufacturers.

\section{Experimental}

Samples

Fish oil samples, totaling 13 from 10 brands, were obtained from pharmacies or natural products stores in Salvador, Bahia, Brazil, during a period of one year, in 2017. Samples of three brands were purchased in two different periods, to evaluate the variability between batches. The samples, batches, and amounts of fatty acids described on the label of each product are listed in Table 1.

\section{Materials}

Methyl ester standards of cis-5,8,11,14,17 eicosapentaenoic acid (EPA) and cis-4,7,10,13,16,19

Table 1. Fish oil samples: expiration date and reported amounts of EPA and DHA per capsule

\begin{tabular}{lccc}
\hline Sample & Expiration date & EPA / (g per capsule $)$ & DHA / (g per capsule) \\
\hline A1 & $11 / 2018$ & 0.1800 & 0.1200 \\
A2 & $11 / 2018$ & 0.1733 & 0.1033 \\
B1 & $08 / 2018$ & 0.1800 & 0.1200 \\
B2 & $02 / 2019$ & 0.1800 & 0.1200 \\
C1 & $10 / 2018$ & 0.1800 & 0.1200 \\
C2 & $01 / 2019$ & 0.1800 & 0.1200 \\
D & $04 / 2018$ & 0.1666 & 0.1333 \\
E & $04 / 2019$ & 0.1800 & 0.1200 \\
F & $02 / 2018$ & 0.1800 & 0.1200 \\
G & $07 / 2019$ & 0.1800 & 0.1200 \\
H & $01 / 2020$ & 0.2000 & 0.1000 \\
I & $06 / 2019$ & 0.3300 & 0.2200 \\
J & $05 / 2019$ & 0.1800 & 0.1200 \\
\hline
\end{tabular}

EPA: eicosapentaenoic acid; DHA: docosahexaenoic acid. 
docosahexaenoic acid (DHA), as well as of FAME mix $\mathrm{C}_{8}-\mathrm{C}_{24}$ were purchased from Supelco ${ }^{\circledast}$ (Sigma-Aldrich, Bellefonte, PA, USA); linoleic acid P.A. and hexane P.A. were available from Aldrich (Bellefonte, PA, USA); HPLC grade methanol and sodium chloride P.A. were from Baker (Phillipsburg, USA); potassium hydroxide P.A. and sulfuric acid P.A. were purchased from Qhemis (São Paulo, Brazil); ultrapure water was obtained from a Barnstead NANOpure Diamond $^{\mathrm{TM}}$ purifier. An analytical balance from Satorius, model TE214S, was used to prepare standard solutions and samples.

\section{Standard solutions}

Stock solutions at concentrations of $1000 \mathrm{mg} \mathrm{L}^{-1}$ were prepared from methyl esters standards of EPA and DHA, as well as from the FAME mix $\mathrm{C}_{8}-\mathrm{C}_{24}$. From these, solutions at smaller concentrations were obtained to construct the calibration curves and to optimize the method. The concentration ranges used were 1.0 to $10 \mathrm{mg} \mathrm{L}^{-1}$ for the methyl esters of oleic, linoleic and linolenic acids, and 5 to $100 \mathrm{mg} \mathrm{L}^{-1}$ for the methyl esters of EPA and DHA.

\section{Preparation of samples}

Sample preparation was based in a previous work available in the literature ${ }^{26}$ through derivatization of the polyunsaturated fatty acids, present in fish oil capsules in the form of glycerol esters or free acids. However, the procedure was partially modified and optimized to obtain the best responses for the samples evaluated in this work.

Briefly, a $100 \mathrm{mg}$ sample was taken from the capsules using a microsyringe and added into a $15 \mathrm{~mL}$ Falcon tube. Then, $3 \mathrm{~mL}$ of a $0.6 \mathrm{~mol} \mathrm{~L}^{-1}$ solution of potassium hydroxide in methanol was added, followed by stirring for $10 \mathrm{~s}$. The tube was purged with a gentle nitrogen flow, to remove air and prevent oxidation of the compounds, and the solution heated at $70^{\circ} \mathrm{C}$ in a water bath for $10 \mathrm{~min}$ and shaken twice during this heating.

After the oil droplets have disappeared, $3 \mathrm{~mL}$ of a $5 \%$ solution of sulfuric acid in methanol was added and the mixture was cooled; the tube was purged again with nitrogen and then heated at $70{ }^{\circ} \mathrm{C}$ in a water bath for $5 \mathrm{~min}$. After this, $2 \mathrm{~mL}$ of a saturated solution of sodium chloride and $2 \mathrm{~mL}$ of hexane were added, the tube shaken, the mixture centrifuged at $4000 \mathrm{rpm}$ for $10 \mathrm{~min}$ and the organic phase transferred to a $2 \mathrm{~mL}$ vial.

Finally, an aliquot was taken from vial and diluted $(50 \times$ or $100 x)$ with hexane and then injected $(1 \mu \mathrm{L})$ into GC-MS for analysis. The whole procedure was performed in triplicate, using three different capsules for each brand analyzed.

\section{Chromatographic conditions}

The samples were analyzed using a gas chromatograph (Varian 431-GC) coupled to an ion trap mass spectrometer (Varian 200-MS) with an automatic sampler (Varian CP-8410). The column was a PE-FFAP (nitroterephthalic acid modified polyethylene glycol, PEG bonded) ( $30 \mathrm{~m} \times 0.32 \mathrm{~mm}$ ID $\times 0.25 \mu \mathrm{m}$; PerkinElmer, USA).

The column temperature program was: $100{ }^{\circ} \mathrm{C}$ for 2 min, increasing at $5{ }^{\circ} \mathrm{C} \mathrm{min}^{-1}$ up to $240{ }^{\circ} \mathrm{C}$ and remaining at $240{ }^{\circ} \mathrm{C}$ for $8 \mathrm{~min}$, with total running time of $38 \mathrm{~min}$. Helium was used as the carrier gas $\left(0.8 \mathrm{~mL} \mathrm{~min}^{-1}\right)$ and the injector was operated in split mode $(20: 1)$ at $240{ }^{\circ} \mathrm{C}$.

The mass spectrometer was operated under the following conditions: trap temperature, $240{ }^{\circ} \mathrm{C}$; manifold temperature, $70{ }^{\circ} \mathrm{C}$; transfer line temperature, $240{ }^{\circ} \mathrm{C}$; ionization energy, $70 \mathrm{eV}$. The samples were analyzed in the full scan mode (SCAN), with a mass range of 10 to 400 a.m.u.

\section{Results and Discussion}

\section{Method optimization}

Long chain polyunsaturated fatty acids are present in fish oil capsules as triacylglycerol esters, although small fractions may also be present as free acids. The derivatization procedure aims to transform them into methyl esters, in order to perform the GC-MS analysis.

The procedure used was based in a previous work, ${ }^{26}$ with modifications in the original conditions, which were: concentration of $\mathrm{KOH}$ solution in methanol, $0.5 \mathrm{~mol} \mathrm{~L}^{-1}$; volume of the $\mathrm{KOH}$ solution, $3 \mathrm{~mL}$; heating time, $20 \mathrm{~min}$; temperature, $60^{\circ} \mathrm{C}$; and use of boron trifluoride in methanol as a derivatization agent. Thus, four variables were evaluated: $\mathrm{KOH}$ concentration, temperature, heating time and acid $\left(\mathrm{H}_{2} \mathrm{SO}_{4}\right)$ concentration. Each of the four variables was tested at three different levels, taking into account the replacement of boron trifluoride by sulfuric acid as catalyst. All experiments were performed in triplicate.

At final, compared to the original procedure, the optimized method of this work had changes in the $\mathrm{KOH}$ concentration, reaction temperature and heating time, besides replacement of boron trifluoride by sulfuric acid.

Basic catalysts are very common and widely used in transesterification reactions, since they offer faster reaction processes and more moderate conditions, when compared to acid catalysts. The best reaction condition in this work 
was obtained with a $\mathrm{KOH}$ concentration of $0.6 \mathrm{~mol} \mathrm{~L}^{-1}$, slightly higher than in the previous work. ${ }^{26}$

The reaction temperature aims to promote the hydrolysis and methylation of the fatty acids, present as triacylglycerols or free fatty acids. The applied temperature affects the product yield; higher temperatures usually lead to better reaction yields. However, much high temperatures may also facilitate undesirable processes, such as degradation and/or evaporation, leading to product losses. ${ }^{16}$ In this work, the best condition found for the reaction temperature was $70{ }^{\circ} \mathrm{C}$, higher than in the previous work.

The heating time, as well as the reaction temperature, is a factor which governs the reaction rate and its total yield. The heating time depends on the temperature at which the reaction is carried. In general, the higher the reaction temperature, the lower the total time. In this work, the best condition found for the heating time was $10 \mathrm{~min}$, half of that found in the previous work.

In the presence of methanol, acid catalysts are able not only to transesterify triglycerides and other lipids but also to esterify the free fatty acids. The most common acid catalysts employed for this purpose are $\mathrm{BF}_{3}, \mathrm{H}_{2} \mathrm{SO}_{4}$ and $\mathrm{HCl}^{28}$ In this work the acid catalyst employed was sulfuric acid, in replacement to the boron trifluoride. Usually, the reaction yield is directly proportional to the $\mathrm{H}_{2} \mathrm{SO}_{4}$ concentration. In this way, the acid concentration was set between 3 and 5\%. Amongst the three concentrations evaluated, the best results were obtained with the highest
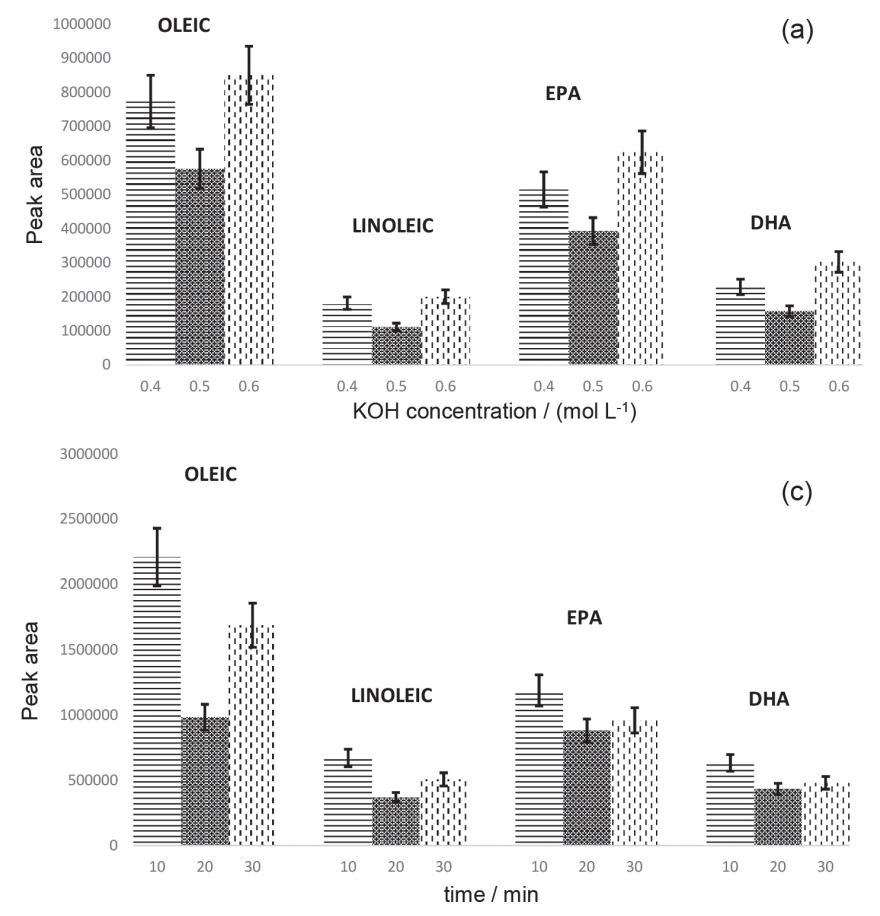

one, namely $5 \%$, corroborating the statement above, while the volume employed was $3 \mathrm{~mL}$.

The results obtained in the optimization experiments, for all the conditions tested, are illustrated in Figure 1.

\section{Chromatographic analysis}

The development of a GC-MS method takes into account the efficiency of the separation and the symmetry of the chromatographic peaks, along with an unequivocal identification of the analytes, thus proving its capacity to discriminate and identify the fatty acid esters.

The developed GC-MS conditions, as previously described in the Experimental section, were used in the analysis of samples and standards. Figure 2 shows chromatograms obtained from standards of methyl esters of oleic, linoleic, linolenic, EPA, and DHA acids, while Figure 3 shows the chromatogram of one real sample. As can be seen from the figures, the chromatograms obtained show good separations amongst the chromatographic peaks of the analytes of interest.

Furthermore, the mass spectra obtained allowed the identification of compounds, through comparison with spectra available in the electronic library of the equipment.

Figures of merit of the optimized method

The calibration curves were obtained with a minimum
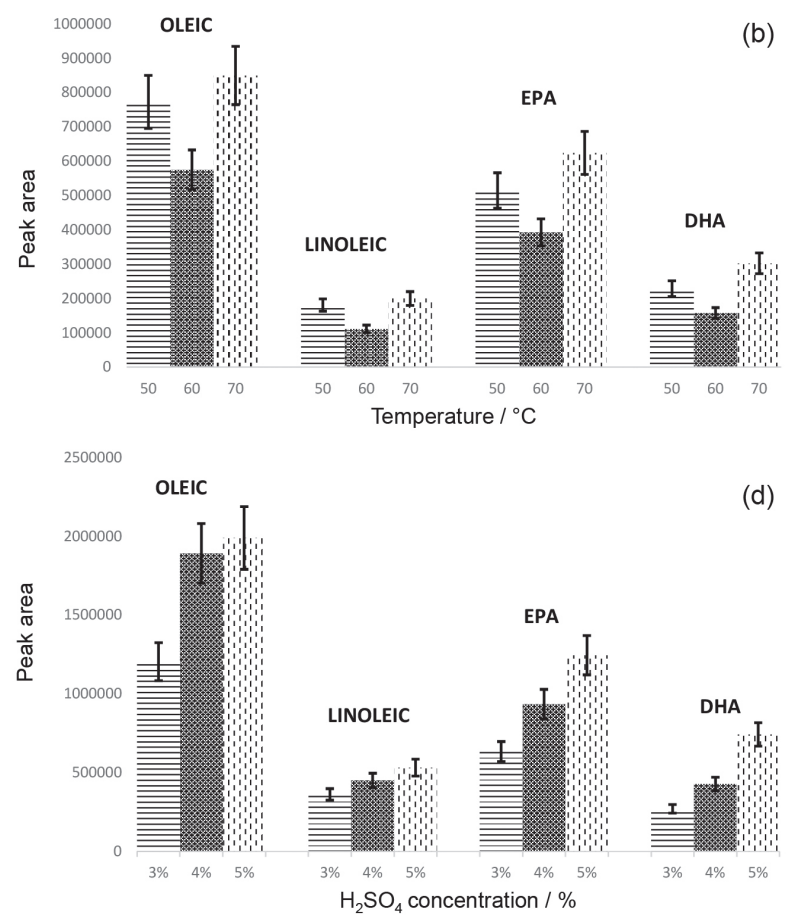

Figure 1. Responses (peak areas) as a function of variation in the evaluated parameters during the optimization of the experimental procedure. (a) $\mathrm{KOH}$ concentration; (b) heating temperature; (c) heating time; (d) $\mathrm{H}_{2} \mathrm{SO}_{4}$ concentration. 

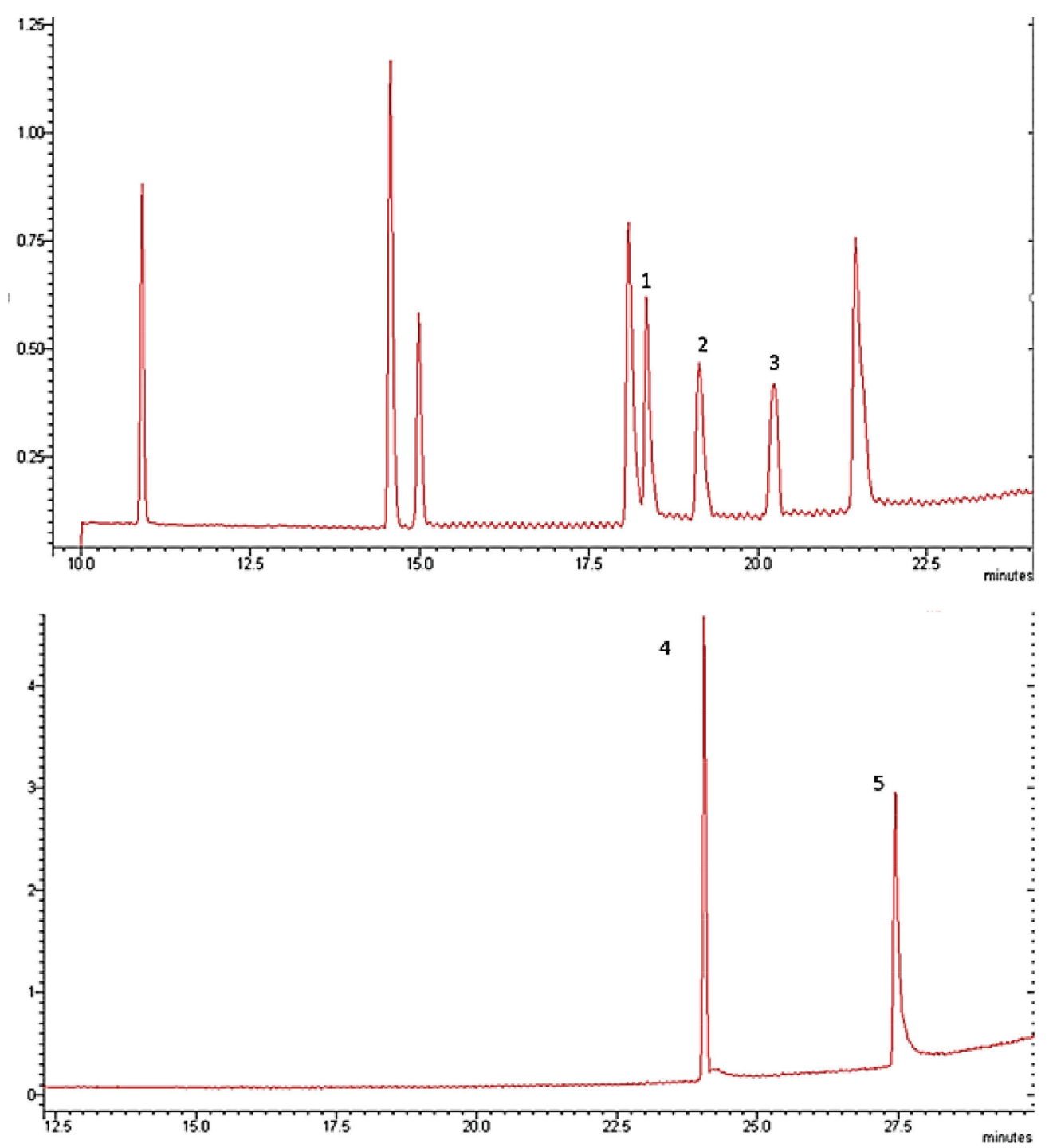

Figure 2. Chromatograms obtained under the conditions described in the Experimental section, for standards of methyl esters: 1: oleic acid; 2: linoleic acid; 3: linolenic acid; 4: EPA and 5: DHA.

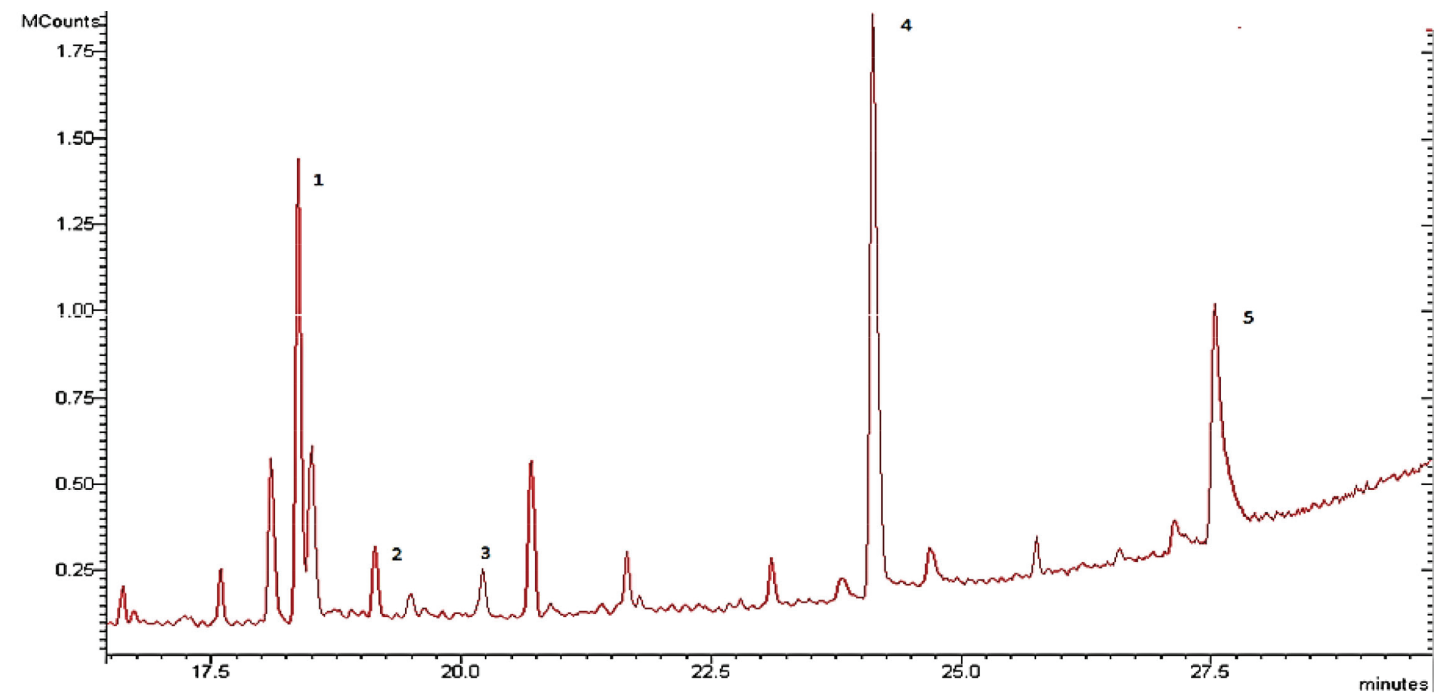

Figure 3. Chromatogram obtained under the conditions described in the Experimental section, for PUFAs methyl esters from a fish oil sample: 1: oleic acid; 2: linoleic acid; 3: linolenic acid; 4: EPA and 5: DHA. 
Table 2. Calibration curve equations, coefficient of determination $\left(\mathrm{R}^{2}\right)$, linearity ranges, limits of detection, and limits of quantification for the optimized method

\begin{tabular}{lccccc}
\hline & $\begin{array}{c}\text { Calibration curve } \\
\text { equation }\end{array}$ & $\mathrm{R}^{2}$ & $\begin{array}{c}\text { Linearity range / } \\
\left(\mathrm{mg} \mathrm{L}^{-1}\right)\end{array}$ & LOD / (mg L L $)$ & LOQ / (mg L-1) \\
\hline Oleic & $y=119278 x-29726$ & 0.9940 & 1.0 to 10 & 0.18 & 0.61 \\
Linoleic & $y=111368 x-32029$ & 0.9945 & 1.0 to 10 & 0.18 & 0.63 \\
Linolenic & $y=100118 x-26382$ & 0.9949 & 1.0 to 10 & 0.13 & 0.46 \\
EPA & $y=58583 x-94900$ & 0.9930 & 5 to 100 & 0.16 & 0.55 \\
DHA & $y=60704 x-153997$ & 0.9925 & 5 to 100 & 0.18 & 0.60 \\
\hline
\end{tabular}

LOD: limits of detection; LOQ: limits of quantification; EPA: eicosapentaenoic acid; DHA: docosahexaenoic acid.

of 6 and up to 9 concentration levels. Table 2 shows the values obtained for the linearity ranges, the equations of the calibration curves, the determination coefficients $\left(\mathrm{R}^{2}\right)$ and the limits of detection (LOD) and quantification (LOQ) for the five analytes.

The optimized method showed good linearity for the fatty acids studied, in the range of 1.0 to $10 \mathrm{mg} \mathrm{L}^{-1}$ for oleic, linoleic, and linolenic acids and 5 to $100 \mathrm{mg} \mathrm{L}^{-1}$ for EPA and DHA, both within the range normally found in fish oil capsules. The $\mathrm{R}^{2}$ values were equal or greater than 0.9925 .

The LOD represents the lowest concentration of a given substance which can be detected, but not quantified, using a certain experimental procedure; while the LOQ represents the lowest concentration of a given substance which can be measured using a given experimental procedure. ${ }^{29,30}$

The LOD and LOQ values were determined through the chromatographic analysis of standards at decreasing concentrations, up to the lowest detectable level. LOD and LOQ were then calculated, respectively, as the concentrations corresponding to 3 and 10 times the standard deviation of the peak areas, obtained from 7 measurements of the standard.

In a previous study ${ }^{26}$ using GC-MS as the determination technique, limits of detection and quantification were, respectively, 0.08 and $0.15 \mathrm{mg} \mathrm{L}^{-1}$ for EPA and 0.21 and $0.60 \mathrm{mg} \mathrm{L}^{-1}$ for DHA. While for EPA lower limits were obtained, for DHA the LOQ was similar and the LOD slightly higher than those found in this study. In another study, ${ }^{31}$ with palmitic, stearic, oleic, linoleic, and linolenic acids, LOD varied between 0.43 and $1.91 \mathrm{mg} \mathrm{L}^{-1}$, whereas LOQ ranged from 1.29 to $5.10 \mathrm{mg} \mathrm{L}^{-1}$, higher than those obtained in this work.

In the evaluation of the method precision, the samples were firstly derivatized and then analyzed according to the described experimental procedure. For the intraday precision, three different capsules of the same brand and lot were analyzed on the same day, whereas for interday precision, three different capsules of the same brand and lot were analyzed each day for five consecutive days. Table 3 shows the calculated results for the interday and intraday precisions.

Table 3. Determined values for interday and intraday precisions

\begin{tabular}{lcc}
\hline Fatty acid & $\begin{array}{c}\text { Interday precision } \\
(\mathrm{n}=15) / \%\end{array}$ & $\begin{array}{c}\text { Intraday precision } \\
(\mathrm{n}=3) / \%\end{array}$ \\
\hline Oleic & 3.45 & 3.75 \\
Linoleic & 3.62 & 0.77 \\
Linolenic & 4.03 & 6.72 \\
EPA & 2.69 & 3.53 \\
DHA & 1.57 & 6.54 \\
\hline
\end{tabular}

EPA: eicosapentaenoic acid; DHA: docosahexaenoic acid.

The results for interday and intraday precision ranged, respectively, between $1.57-4.03 \%$ and $0.77-6.72 \%$. These values are close to those found in a previous work ${ }^{32}$ of FAMEs determination in human plasma, although higher than those found in other case. ${ }^{26}$ Nevertheless, they can be considered suitable for determining these analytes in the selected matrix.

The accuracy of the method was assessed through recovery tests. The procedure adopted was to add, in triplicate, a known mass (ca. $2 \mathrm{mg}$ ) of a pure linoleic acid standard to $100 \mathrm{mg}$ of fish oil samples, for which the original quantity of this acid had previously been determined. The amount of linoleic acid which was added was nearly equivalent, in average, to the original amount of this acid previously determined in samples.

The sample was then subjected to the derivatization process as described above. The recovery values were then calculated by comparing the total mass of linoleic acid determined in the samples with the expected theoretical mass.

The recovery study was performed only with linoleic acid, since this acid was ready to use in the laboratory in a pure form and in sufficient quantities to carry out the tests, unlike EPA and DHA. Furthermore, as the available EPA and DHA standard solutions were already in the form of esters, they were improper to evaluate recoveries resulting 
of the whole procedure. Linoleic acid, instead, was used in the form of free fatty acid, permitting to carry out the derivatization procedure and thus evaluate the recoveries in a more complete way. A possible alternative to bypass this problem in future works would be to use reference materials.

The recovery values found in this way ranged from 73 to $85 \%$, with a mean of $77.6 \%$.

\section{Method application}

The optimized method was applied in the analysis of ten brands of encapsulated fish oil, from natural products stores or popular pharmacies in Salvador. All samples were analyzed in triplicate.
Table 4 shows the results obtained for all the polyunsaturated fatty acids determined, and also compares the values reported by manufacturers for the amounts $\left(\mathrm{mg} \mathrm{g}^{-1}\right)$ of EPA and DHA in the capsules, with those found in this study. The $\omega-6: \omega-3$ ratios, as well as the calculated sum for the amounts of EPA and DHA, are also included.

The concentration values reported by the manufacturers, for the sum of EPA and DHA, ranged from 191.1 to $550 \mathrm{mg} \mathrm{g}^{-1}$, with an average value of $287.9 \pm 94.4 \mathrm{mg} \mathrm{g}^{-1}$, while those determined in this study ranged from 160.6 to $360.4 \mathrm{mg} \mathrm{g}^{-1}$, with an average value of $197.3 \pm 50.7 \mathrm{mg} \mathrm{g}^{-1}$. The best agreement between the determined and reported values was obtained for sample $\mathrm{H}$, for which the determined result agreed in $96 \%$ with the reported value. On the other hand, the lowest (sample B2) agreed only in 55\%.

Table 4. Values for determined (value \pm relative standard deviation (RSD)) and informed concentrations of oleic, linoleic, linolenic, EPA, and DHA acids; $\omega-6: \omega-3$ ratios; agreement between determined and informed concentrations of EPA and DHA and values for the EPA + DHA sum

\begin{tabular}{|c|c|c|c|c|c|c|c|c|c|c|}
\hline San & & Oleic & Linoleic & Linolenic & EPA & DHA & $\omega-6: \omega-3$ & $\begin{array}{l}\text { Deter } \\
\text { inform }\end{array}$ & $\begin{array}{l}\text { ined/ } \\
\text { ed / \% }\end{array}$ & $\mathrm{EPA}+\mathrm{DHA}$ \\
\hline A1 & determined / $\left(\mathrm{mg} \mathrm{g}^{-1}\right)$ & $20.36 \pm 1.07$ & $12.2 \pm 1.12$ & $0.79 \pm 0.03$ & $127.45 \pm 10.81$ & $61.36 \pm 8.56$ & 0.0643 & 99.11 & 71.60 & 188.81 \\
\hline & informed / $\left(\mathrm{mg} \mathrm{g}^{-1}\right)$ & NI & NI & NI & 128.6 & 85.7 & & & & 214.3 \\
\hline A2 & determined $/\left(\mathrm{mg} \mathrm{g}^{-1}\right)$ & $29.73 \pm 15.58$ & $12.57 \pm 1.45$ & $0.76 \pm 0.03$ & $123.85 \pm 6.08$ & $50.42 \pm 7.49$ & 0.0718 & 100.04 & 68.32 & 174.27 \\
\hline & informed / $\left(\mathrm{mg} \mathrm{g}^{-1}\right)$ & NI & NI & NI & 123.8 & 73.8 & & & & 197.6 \\
\hline B1 & determined / $\left(\mathrm{mg} \mathrm{g}^{-1}\right)$ & $21.58 \pm 1.88$ & $13.37 \pm 0.87$ & $1.34 \pm 0.68$ & $125.23 \pm 6.67$ & $66.64 \pm 10.82$ & 0.0692 & 69.57 & 55.53 & 191.87 \\
\hline & informed / $\left(\mathrm{mg} \mathrm{g}^{-1}\right)$ & NI & NI & NI & 180 & 120 & & & & 300 \\
\hline B2 & determined / $\left(\mathrm{mg} \mathrm{g}^{-1}\right)$ & $18.59 \pm 1.92$ & $37.0 \pm 16.96$ & $4.72 \pm 4.93$ & $126.43 \pm 5.51$ & $38.8 \pm 5.25$ & 0.2177 & 70.24 & 32.33 & 165.23 \\
\hline & informed / $\left(\mathrm{mg} \mathrm{g}^{-1}\right)$ & NI & NI & NI & 180 & 120 & & & & 300 \\
\hline $\mathrm{C} 1$ & determined / $\left(\mathrm{mg} \mathrm{g}^{-1}\right)$ & $18.96 \pm 1.50$ & $14.64 \pm 2.52$ & $0.86 \pm 0.05$ & $114.99 \pm 5.30$ & $45.65 \pm 2.07$ & 0.0907 & 89.42 & 53.27 & 160.64 \\
\hline & informed / $\left(\mathrm{mg} \mathrm{g}^{-1}\right)$ & NI & NI & NI & 128.6 & 85.7 & & & & 214.3 \\
\hline $\mathrm{C} 2$ & determined / $\left(\mathrm{mg} \mathrm{g}^{-1}\right)$ & $18.93 \pm 1.44$ & $13.33 \pm 0.73$ & $4.77 \pm 5.41$ & $126.76 \pm 14.01$ & $43.53 \pm 8.82$ & 0.0761 & 98.57 & 50.79 & 170.29 \\
\hline & informed / $\left(\mathrm{mg} \mathrm{g}^{-1}\right)$ & NI & NI & NI & 128.6 & 85.7 & & & & 214.3 \\
\hline D & determined / $\left(\mathrm{mg} \mathrm{g}^{-1}\right)$ & $26.00 \pm 0.80$ & $14.78 \pm 0.63$ & $1.27 \pm 0.03$ & $116.64 \pm 6.07$ & $71.92 \pm 3.87$ & 0.0779 & 69.97 & 53.95 & 188.56 \\
\hline & informed / $\left(\mathrm{mg} \mathrm{g}^{-1}\right)$ & NI & NI & NI & 166.7 & 133.3 & & & & 300 \\
\hline $\mathrm{E}$ & determined / $\left(\mathrm{mg} \mathrm{g}^{-1}\right)$ & $19.77 \pm 3.73$ & $17.38 \pm 3.31$ & $0.94 \pm 0.11$ & $133.52 \pm 16.27$ & $69.46 \pm 5.74$ & 0.0852 & 74.18 & 57.88 & 202.98 \\
\hline & informed / (mg g $\left.{ }^{-1}\right)$ & $\mathrm{NI}$ & NI & 90 & 180 & 120 & & & & 300 \\
\hline $\mathrm{F}$ & determined / $\left(\mathrm{mg} \mathrm{g}^{-1}\right)$ & $21.28 \pm 2.01$ & $19.02 \pm 10.06$ & $0.89 \pm 0.06$ & $129.1 \pm 7.57$ & $69.24 \pm 10.29$ & 0.0955 & 71.72 & 57.70 & 198.34 \\
\hline & informed / $\left(\mathrm{mg} \mathrm{g}^{-1}\right)$ & NI & NI & NI & 180 & 120 & & & & 300 \\
\hline G & determined / $\left(\mathrm{mg} \mathrm{g}^{-1}\right)$ & $17.89 \pm 1.46$ & $13.46 \pm 2.16$ & $0.77 \pm 0.04$ & $116.09 \pm 7.80$ & $66.88 \pm 7.28$ & 0.0733 & 64.49 & 55.73 & 182.97 \\
\hline & informed / $\left(\mathrm{mg} \mathrm{g}^{-1}\right)$ & NI & NI & NI & 180 & 120 & & & & 300 \\
\hline $\mathrm{H}$ & determined / $\left(\mathrm{mg} \mathrm{g}^{-1}\right)$ & $28.26 \pm 1.46$ & $29.28 \pm 14.90$ & $1.35 \pm 0.22$ & $130.06 \pm 9.53$ & $53.41 \pm 14.71$ & 0.1584 & 102.09 & 83.85 & 183.47 \\
\hline & informed / ( $\left.\mathrm{mg} \mathrm{g}^{-1}\right)$ & NI & NI & NI & 127.4 & 63.7 & & & & 191.1 \\
\hline I & determined / $\left(\mathrm{mg} \mathrm{g}^{-1}\right)$ & $11.59 \pm 0.15$ & $6.76 \pm 0.38$ & $3.95 \pm 4.83$ & $240.65 \pm 24.44$ & $119.78 \pm 3.68$ & 0.0186 & 72.92 & 54.45 & 360.43 \\
\hline & informed / ( $\left.\mathrm{mg} \mathrm{g}^{-1}\right)$ & NI & NI & NI & 330 & 220 & & & & 550 \\
\hline $\mathrm{J}$ & determined / $\left(\mathrm{mg} \mathrm{g}^{-1}\right)$ & $34.39 \pm 6.48$ & $157.44 \pm 12.44$ & $1.75 \pm 0.41$ & $26.86 \pm 0.98$ & ND & 5.5030 & 14.92 & - & - \\
\hline & informed $/\left(\mathrm{mg} \mathrm{g}^{-1}\right)$ & NI & NI & NI & 180 & 120 & & & & \\
\hline
\end{tabular}

EPA: eicosapentaenoic acid; DHA: docosahexaenoic acid; NI: not informed; ND: not detected. 
In this case (sample B2), the main reason for the discrepancy was the difference between the DHA concentrations, 120.0 and $38.8 \mathrm{mg} \mathrm{g}^{-1}$, respectively, for the reported and the determined values. On average, the determined quantities had shown a $72 \%$ agreement with those reported by manufacturers.

It is important to mention that the main contribution to the differences between the reported and determined amounts in each product was almost always from DHA, which could be due to possible losses in this compound by oxidation processes.

Among the ten acquired brands, three of them (A, B, and C) were analyzed in two different lots. Among these, two (A1 and $\mathrm{A} 2 ; \mathrm{C} 1$ and $\mathrm{C} 2$ ) have shown good agreement between the results, taking into account the sum of EPA and DHA (A1 $=188.8 \mathrm{mg} \mathrm{g}^{-1}$ and $\mathrm{A} 2=174.3 \mathrm{mg} \mathrm{g}^{-1} ; \mathrm{C} 1=160.6 \mathrm{mg} \mathrm{g}^{-1}$ and $\mathrm{C} 2=170.3 \mathrm{mg} \mathrm{g}^{-1}$ ) with differences of 8 and $6 \%$, respectively, between lots. This suggests that both the production processes and the raw material used maintained good reproducibility between the batches of the brands. For samples A1 and A2 the manufacture dates corresponded to the same month (Nov/2016), while for samples C1 and C2 there was a difference of three months, with sample $\mathrm{C} 1$ from October 2016 and sample C2 from January 2017.

On the other hand, brand B varied $14 \%\left(B 1=191.9 \mathrm{mg} \mathrm{g}^{-1}\right.$ and $\mathrm{B} 2=165.2 \mathrm{mg} \mathrm{g}^{-1}$ ). This was also the brand that had shown the greatest discrepancy between the reported and calculated concentrations in the sum EPA and DHA.

Although no brand included information on the label about the amounts of oleic, linoleic and linolenic acids that were present in the capsules, these were also determined in this study, with the results presented in Table 4. The oleic acid was found in a concentration range between 11.6 and $34.4 \mathrm{mg} \mathrm{g}^{-1}$; linoleic acid in the range of 12.2 to $37.0 \mathrm{mg} \mathrm{g}^{-1}$ (except for sample $\mathrm{J}$ in which the concentration was $157.4 \mathrm{mg} \mathrm{g}^{-1}$ ) and linolenic acid in the concentration range of 0.8 to $4.8 \mathrm{mg} \mathrm{g}^{-1}$.

A special attention must be given to sample $\mathrm{J}$, as the determined amount of EPA was only $26.9 \mathrm{mg} \mathrm{g}^{-1}$, or about $14.9 \%$ of the informed value, while DHA was not detected. In addition, it contained significantly higher amounts of oleic and, especially, linoleic acid, the amount of which was about nine times higher than the average found in the others. The abnormal behavior of this sample can also be figured out in its extremely high $\omega-6: \omega-3$ ratio. These results indicate a probable adulteration of this brand, possibly by the addition of vegetable oils that are rich in these acids, such as soybean oil. Other authors have previously reported this type of adulteration. ${ }^{33,34}$

Despite carried studies which state that the intake of $\omega-3$ polyunsaturated fatty acids has several beneficial effects, ${ }^{35}$ literature data points out that western diets are currently deficient in fatty acids of this series, while at the same time they have excessive amounts of fatty acids of the $\omega-6$ series. Studies on ancestral diets revealed a ratio of $\omega-6: \omega-3$ of $1: 1$, whereas currently this ratio tends to be 10:1 or even 20:1 in certain cases. ${ }^{36}$

However, the Food and Agriculture Organization of the United Nations (FAO) ${ }^{35}$ does not establish specific recommendations for $\omega-6: \omega-3$ ratios in diets, provided that the intake of fatty acids of these series is within the recommendations set by that organization. In this way, the FAO's guidance is that for adult men and women, the intake of EPA plus DHA should be in the range of $0.250 \mathrm{~g} \mathrm{day}^{-1}$, without sufficient evidence to set individually a desirable minimum EPA or DHA dose. On the other way, for pregnant or lactating women the minimum dose should be $0.300 \mathrm{~g} \mathrm{day}^{-1}$, with at least $0.200 \mathrm{~g} \mathrm{day}^{-1}$ of DHA. ${ }^{35}$ The determined amounts for the brands analyzed in this work (Table 4) suggest that, to reach the recommended daily values for the sum of EPA and DHA, adults would need to consume more than $1 \mathrm{~g}$ of the encapsulated fish oil, which would be equivalent on average to the daily consumption of two capsules. This agrees with the dosage suggested on the labels of the acquired products. However, taking into account the recommendation of at least $0.200 \mathrm{~g} \mathrm{day}^{-1}$ of DHA for pregnant or lactating women, the daily intake should be at least four capsules.

\section{Conclusions}

The analytical method optimized in this work was able to identify and quantify oleic, linoleic, linolenic, EPA, and DHA acids, after their derivatization to methyl esters, in samples of encapsulated fish oil marketed in Salvador, at varying concentrations in the range of $\mathrm{mg} \mathrm{g}^{-1}$.

In the analyzed brands, the combined concentrations of EPA and DHA were between 160.6 and $360.4 \mathrm{mg} \mathrm{g}^{-1}$ with an average result of $197.3 \pm 50.7 \mathrm{mg} \mathrm{g}^{-1}$. The best agreement between the manufacturer's reported value on the label and the calculated value was achieved for brand $\mathrm{H}$, with a $96 \%$ agreement between values. On the other hand, the lowest was for sample B2, with only 55\% of agreement between values, the main reason for this being the difference in DHA values.

According to FAO recommendations, the daily intake of EPA plus DHA for adults should be in the range of $0.250 \mathrm{~g}$, while for pregnant women it should be $0.300 \mathrm{~g}$, of which at least $0.200 \mathrm{~g}$ is DHA. For most adults this would be equivalent to about $2 \mathrm{~g}$ of the encapsulated fish oil, or an average of two capsules per day.

Finally, it is important to emphasize the importance of analyzing other brands that are available in the market, 
as well as different batches of a same brand, in view of significant differences found in certain cases between the values on the label and those determined in the analyzes, in addition to one sample in which a probable adulteration was detected.

\section{Acknowledgments}

The authors are grateful to CAPES and CNPq for the scholarships provided to M. S. C. B. and G. A. C., respectively. We also thank the National Council for Scientific and Technological Development (CNPq), the State of Bahia Foundation for Support to Research (FAPESB), FINEP, BRASKEM and PETROBRAS, for the financial assistance. We are also grateful to Prof Wilson Araujo Lopes for his valuable help with the figures.

\section{References}

1. Sung, J.; Ho, C.-T.; Wang, Y.; Food Funct. 2018, 9, 6081.

2. Andrade, P. M. M.; Carmo, M. G. T.; MN-Metabólica 2006, 8 , 135.

3. Cabo, J.; Alonso, R.; Mata, P.; Br. J. Nutr. 2012, 107, 195.

4. Delgado-Lista, J.; Perez-Martinez, P.; Lopez-Miranda, J.; PerezJimenez, F.; Br. J. Nutr. 2012, 107, 201.

5. Calder, P. C.; Albers, R.; Antoine, J.; Blum, S.; Ferns, G. A.; Folkerts, G.; Br. J. Nutr. 2009, 101, 2.

6. Wang, H.; Wu, Y.; Wang, N.; Yang, L.; Zhou, Y.; Food Chem. 2019, 278, 515.

7. Perini, J. A. L.; Stevanato, F. B.; Sargi, S. C.; Visentainer, J. E. L.; Dalalio, M. M. O.; Matshushita, M.; de Souza, N. E.; Visentainer, J. V.; Rev. Nutr. 2010, 23, 1075.

8. Wang, M.; Chen, H.; Ailati, A.; Chen, W.; Chilton, F. H.; Lowther, W. T.; Chen, Y. Q.; Appl. Microbiol. Biotechnol. 2018, 102, 211.

9. Chen, L.; Wang, L.; Wang, H.; Sun, R.; You, L.; Zheng, Y.; Yuan, Y.; Li, D.; PLoS One 2018, 13, e0196693.

10. Rossato, L. T.; Schoenfeld, B. J.; de Oliveira, E. P.; Clin. Nutr. 2019, DOI: 10.1016/J.CLNU.2019.01.001.

11. Asif, M.; Orient. Pharm. Exp. Med. 2011, 11, 51.

12. Corazza, M. Z.; Tarley, C. R. T.; Microchem. J. 2016, 127, 145.

13. Vianni, R.; Braz-Filho, R.; Quim. Nova 1996, 19, 400.

14. Srigley, C. T.; Rader, J. I.; J. Agric. Food Chem. 2014, 62, 7268.

15. Prato, E.; Biandolino, F.; Parlapiano, I.; Giandomenico, S.; Denti, G.; Calò, M.; Spada, L.; Di Leo, A.; Sci. Total Environ. 2019, 648, 153.

16. Killeen, D. P.; Marshall, S. N.; Burgess, E. J.; Gordon, K. C.; Perry, N. B.; J. Agric. Food Chem. 2017, 65, 3551.

17. Plans, M.; Wenstrup, M. J.; Rodriguez-Saona, L. E.; J. Am. Oil Chem. Soc. 2015, 92, 957.
18. Santos, R. D.; Gagliardi, A. C. M.; Xavier, H. T.; Magnoni, C. D.; Cassani, R.; Lottenberg, A. M. P.; Casella, F. A.; Araújo, D. B.; Cesena, F. Y.; Alves, R. J.; Fenelon, G.; Nishioka, S. A. D.; Faludi, A. A.; Geloneze, B.; Scherr, C.; Kovacs, C.; Tomazzela, C.; Carla, C.; Barrera-Arellano, D.; Cintra, D.; Quintão, E.; Ramos, S.; Arq. Bras. Cardiol. 2013, 100, 1.

19. Marcone, M. F.; Wang, S.; Albabish, W.; Nie, S.; Somnarain, D.; Hill, A.; Food Res. Int. 2013, 51, 729.

20. Vosough, M.; Salemi, A.; Talanta 2007, 73, 30.

21. AOCS Official Method Ce 1i-07; Official Methods and Recommended Practices of the AOCS, $6^{\text {th }}$ ed.; Firestone, D., ed.; AOCS Press: Urbana, USA, 2009.

22. Schneedorferová, I.; Tomčala, A.; Valterová, I.; Food Chem. 2015, 176, 205.

23. Kutzner, L.; Ostermann, A. I.; Konrad, T.; Riegel, D.; Hellhake, S.; Schuchardt, J. P.; Schebb, N. H.; J. Agric. Food Chem. 2017, $65,139$.

24. Ruiz-Chancho, M. J.; Taleshi, M. S.; Goessler, W.; Francesconi, K. A.; J. Anal. At. Spectrom. 2012, 27, 501.

25. Liu, Y.; Jiao, J. G.; Gao, S.; Ning, L. J.; Limbu, S. M.; Qiao, F.; Chen, L. Q.; Zhang, M. L.; Du, Z. Y.; Food Chem. 2019, 277, 515.

26. Yi, T.; Li, S. M.; Fan, J. Y.; Fan, L. L.; Zhang, Z. F.; Luo, P.; Zhang, X. J.; Wang, J. G.; Zhu, L.; Zhao, Z. Z.; Chen, H. B.; Lipids Health Dis. 2014, 13, 190.

27. Picó, Y.; Análise Química de Alimentos - Técnicas; Elsevier: Rio de Janeiro, 2015.

28. Liu, K.-S.; J. Am. Oil Chem. Soc. 1994, 71, 1179.

29. Ribani, M.; Beatriz, C.; Bottoli, G.; Collins, C. H.; Sales, C.; Jardim, F.; Melo, L. F. C.; Quim. Nova 2004, 27, 771.

30. Instituto Nacional de Metrologia(INMETRO); DOQ-CGRE-008: Orientação sobre Validação de Métodos Analíticos; INMETRO, 2011.

31. Li, S. S.; Yuan, R. Y.; Chen, L. G.; Wang, L. S.; Hao, X. H.; Wang, L. J.; Zheng, X. C.; Du, H.; Food Chem. 2015, 173, 133.

32. Ecker, J.; Scherer, M.; Schmitz, G.; Liebisch, G.; J. Chromatogr. B: Anal. Technol. Biomed. Life Sci. 2012, 897, 98.

33. Metcalf, R. G.; James, M. J.; Mantzioris, E.; Cleland, L. G.; Eur. J. Clin. Nutr. 2003, 57, 1605.

34. Galuch, M. B.; Carbonera, F.; Magon, T. F. S.; da Silveira, R.; dos Santos, P. D. S.; Pizzo, J. S.; Santos, O. O.; Visentainer, J. V.; J. Braz. Chem. Soc. 2018, 29, 631.

35. Food and Agriculture Organization of the United Nations (FAO); Fats and Fatty Acids in Human Nutrition-Report of an Expert Consultation; FAO: Rome, 2010.

36. Simopoulos, A. P.; Biomed. Pharmacother. 2002, 56, 365.

Submitted: March 26, 2019

Published online: August 26, 2019 